Available online at GSC Online Press Directory

GSC Biological and Pharmaceutical Sciences

e-ISSN: 2581-3250, CODEN (USA): GBPSC2

Journal homepage: https://www.gsconlinepress.com/journals/gscbps

(RESEARCH ARTICLE)

\title{
Phenotypic characterization of Salmonella typhi isolated from febrile and diarrhea patients in Bauchi, Nigeria
}

\author{
Rabiu Sahal Muhammed *, Inusa Titus, Farouk Ahmed Umar and Ediga Agbo Bede \\ Department of Biological Sciences, Faculty of Sciences, Abubakar Tafawa Balewa University, Bauchi, Nigeria.
}

Publication history: Received on 22 June 2018; revised on 23 July 2018; accepted on 30 July 2018

Article DOI: https://doi.org/10.30574/gscbps.2018.4.3.0053

\begin{abstract}
Salmonella typhi infection occur in most endemic areas. Patients suspected of typhoid fever and diarrhea attending health facilities in Bauchi metropolis were the population studied. 384 stool and blood specimens were collected. The aim of the study was to investigate Salmonella typhi using phenotypic analysis to determine whether the organism pose significance attributes among age group or gender and it is specific with fever and diarrhea in Bauchi metropolis, Bauchi, Nigeria. Blood and stool specimens were first enriched in tetrathionate and selenite F broth respectively before subcultured on selective medium while identification was conducted with some biochemical analysis. Of the 384 blood and stool specimens screened, 178(46.4 \%) yielded significant bacterial growth, while 206(53.6\%) showed no evidence of bacterial growths. Salmonella typhi accounted for $6.2 \%$ of the total bacteria isolated while other Enterobacteriaceae accounted for $93.8 \%$. Distribution of Salmonella typhi were insignificant in the selected health facility using CochranMantel's analysis with male and female at $(\mathrm{P}=0.827)$, and $(\mathrm{P}=0.866)$ in blood and stool specimens respectively. Age groups also shows insignificant attributes to Salmonella typhi investigation at $(\mathrm{P}=0.44)$. It continues to maintain a mainstream focus of difficulty to isolate the organism via culture despite the selective medium used for the study. Therefore, screening and identification for Salmonella typhi at phenotypic level still pose a problem in many Health facility. The research has considerably shown the adverse variability of Salmonella typhi from both samples collected among research inclusions.
\end{abstract}

Keywords: Salmonella typhi; Phenotypic; Blood; Stool; Bauchi

\section{Introduction}

Salmonella typhi infection occurs in most industrialized nations and developing countries at high frequency and is an important public health concern worldwide [1]. In Africa, it has an estimated crude incidence of 362 cases per 100,000 individuals annually [2]. In most endemic areas, approximately $90 \%$ of enteric fever and gastroenteritis are typhoidal/non typhoidal and caused about 216,500 deaths among children and young adults worldwide [3-4]. The agent of typhoid fever causes serious health problem in developing countries due to their unsuitable sewage treatments, poor standards of hygiene and unavailability of potable drinking water [5]. It is mostly encountered in tropical and subtropical countries including Nigeria where it constitutes significant sources of morbidities and mortalities [6].

The incidence of typhoid salmonellosis (which is caused by Salmonella enterica typhi) is increasing worldwide, causing millions of infections and many deaths in the human population each year.

Salmonella enterica serovar Typhi are gram-negative rods, non-spore forming, motile and microscopic living creatures. They are oxidase-negative, catalase-positive, non-lactose fermenters, producing acid from D-glucose usually at times

\footnotetext{
${ }^{*}$ Corresponding author

E-mail address: sahalrab@yahoo.com
}

Copyright (C) 2018 Author(s) retain the copyright of this article. This article is published under the terms of the Creative Commons Attribution Liscense 4.0. 
accompanied with the production of carbon dioxide and some utilize citrate as a sole carbon source [7]. Phenotypic characterization via culture still remains the goal standard for identification of Salmonella typhi. The research will provide a baseline for phenotypic characterization of Salmonella typhi from blood and stool specimen of febrile and diarrhea patients attending hospital facility.

\section{Materials and methods}

\subsection{Collection of samples}

Blood were drawn aseptically using $5 \mathrm{ml}$ syringe and needle [8]. About $2 \mathrm{ml}$ of blood were collected from patients. The blood was aseptically transferred to $8 \mathrm{ml}$ tetrathionate broth tube and incubated. Tubes that shows no turbidity were kept for 48, 72 hours respectively. Each tube was carefully labeled with the patient's number already indicated in the research consent form [8].

For collection of stool specimen, the subjects were provided with clean wide-mouthed containers and about $2 \mathrm{~g}$ of the stool were transferred unto tubes containing $8 \mathrm{ml}$ of Selenite F Broth and was incubated at $37{ }^{\circ} \mathrm{C}$ for 24 hours [8-9].

\subsection{Microbiological analysis}

\subsubsection{Processing of blood specimens}

The collected blood and tetrathionate broth were incubated overnight at $37{ }^{\circ} \mathrm{c}$ for 18 to 24 hours. Tubes that shows turbidity were sub-cultured each from each of the containers unto freshly prepared and dried Salmonella-Shigella agar (SSA) and MacConkey agar (Biotec) and incubated at $37^{\circ} \mathrm{C}$.

\subsubsection{Processing of stool specimens}

The stool samples were first inoculated into the enrichment medium (selenite-F broth) and after incubation for 24 hours at $37^{\circ} \mathrm{C}$ each was sub-cultured unto Salmonella-Shigella agar and MacConkey agar (MCA). The SSA and MCA plates were incubated overnight at $37^{\circ} \mathrm{C}$ and examined for growth [9].

\subsection{Characterization of isolates}

\subsubsection{Sugar fermentation tests}

Nutrient broth cultures were prepared. Bijou bottles containing the basal medium and appropriate prepared carbohydrate (mannitol, maltose, dulcitol, sucrose and glucose) were inoculated with drop of the nutrient broth suspension of the test isolate and were loosely capped and incubated at $35 \stackrel{\circ}{\circ}$ overnight. Each was observed for change in colour from amber to red and for gas production (in the medium filled inverted Durham tube) [10-12].

\subsubsection{Urease test}

The test organisms were inoculated heavily on the entire slope surface of the urea agar slants prepared in caped tubes. The tubes were placed in racks and incubated at $37^{\circ} \mathrm{C}$ up to 48 hours. Tubes were thereafter examined for change of colour from plain to pink [9].

\subsubsection{Indole test}

Inoculate a tube containing $5 \mathrm{ml}$ of the tryptone/tryptophan medium with the suspected colony. Incubate at $37{ }^{\circ} \mathrm{C}$ for $24 \mathrm{~h}$. After incubation and $1 \mathrm{ml}$ of the Kovacs reagent was added. The formation of a red ring indicates a positive reaction. A yellow-brown ring indicates a negative reaction [9].

\subsubsection{Hydrogen sulphide production}

Test organisms were inoculated into the triple sugar iron agar slants contained in test tubes. These were incubated at $35-37{ }^{\circ} \mathrm{C}$ for up to 48 hours. After incubation, the TSI agar media were checked for blackening and change in colour from amber to red at the bottom of the tube [9].

\subsubsection{Serological identification (Serotyping)}

Suspected colonies were picked and sub-cultured unto moist nutrient agar slopes in MacCartney bottles. These were incubated for minimum of 4 hours. One to two loopfuls of the agar cultures were mixed with normal saline on clean 
microscope slides to form a paste. A drop each of the $\mathrm{O}$ and $\mathrm{H}$ polyvalent sera were added and further mixed with the organisms on the slide. Positive results were indicated by visible agglutination within 30 seconds. Slide tests were repeated for the positive cultures using single factor sera [13-15].

\subsubsection{Microbact kit examination}

Serological confirmed isolates were subjected to Salmonella microbact kit and result were obtain in percentages [9].

\section{Results and discussion}

A total of 384 patients were recruited to the study at three health facilities from June 2016 to November 2016. One hundred and fifty-seven patients (40.9\%) and 227 equivalents to (59.1\%) were males and females enrolled in the three health facilities accounting to three simultaneous health factors of fever (231), diarrhea (117) and fever/diarrhea (36) equivalent to $60.2 \%, 30.5 \%$ and $9.3 \%$ respectively. The patient's age ranged from 1 year to 70 years with a mean of 38.7 and standard deviation of 19 . Out of 384 participants, 122 were obtained from ATBUTH, 207 from Primary health care facility of Tashan Babiye and 55 from NIIMA Consultants respectively (Table 1). The mean age of the females was significantly different from the mean age of the males. There was no significant difference in the age of the participants across gender $(X 2=0.57 \mathrm{df}=383)$.

Table 1 Distribution of subjects based on age and sex in the three selected hospitals in Bauchi

\begin{tabular}{|c|c|c|c|c|c|c|c|c|c|c|c|c|c|c|c|c|c|c|c|}
\hline \multirow{4}{*}{$\begin{array}{l}\text { Age } \\
\text { group }\end{array}$} & \multicolumn{18}{|c|}{ Health facilities } & \multirow{4}{*}{ Total } \\
\hline & \multicolumn{6}{|c|}{ ATBUTH $(n=122)$} & \multicolumn{6}{|c|}{ BABIYE $(n=207)$} & \multicolumn{6}{|c|}{ NIIMA $(n=55)$} & \\
\hline & \multicolumn{3}{|c|}{ Male } & \multicolumn{3}{|c|}{ Female } & \multicolumn{3}{|c|}{ Male } & \multicolumn{3}{|c|}{ Female } & \multicolumn{3}{|c|}{ Male } & \multicolumn{3}{|c|}{ Female } & \\
\hline & $\mathbf{F}$ & D & F/D & $\mathbf{F}$ & D & F/D & $\mathbf{F}$ & D & F/D & $\mathbf{F}$ & D & F/D & $\mathbf{F}$ & D & F/D & $\mathbf{F}$ & D & F/D & \\
\hline $1-10$ & 3 & 8 & 1 & 11 & 15 & 2 & 16 & 18 & 1 & 37 & 26 & 9 & 14 & 2 & 1 & 6 & 4 & 1 & 175 \\
\hline $11-20$ & 7 & 6 & 2 & 9 & 4 & 1 & 22 & 5 & 2 & 15 & 3 & 3 & 7 & 0 & 0 & 3 & 1 & 3 & 93 \\
\hline $21-30$ & 6 & 2 & 0 & 13 & 3 & 0 & 4 & 1 & 2 & 3 & 1 & 2 & 3 & 0 & 0 & 1 & 0 & 1 & 42 \\
\hline $31-40$ & 1 & 0 & 0 & 2 & 3 & 0 & 1 & 0 & 0 & 4 & 4 & 0 & 3 & 0 & 0 & 0 & 0 & 0 & 18 \\
\hline $41-50$ & 3 & 1 & 0 & 1 & 1 & 0 & 0 & 4 & 0 & 1 & 0 & 0 & 0 & 0 & 0 & 1 & 0 & 0 & 12 \\
\hline $51-60$ & 2 & 0 & 0 & 3 & 0 & 1 & 0 & 1 & 0 & 11 & 1 & 0 & 1 & 0 & 0 & 0 & 0 & 0 & 20 \\
\hline $61-70$ & 3 & 0 & 2 & 3 & 3 & 0 & 1 & 0 & 0 & 7 & 0 & 2 & 1 & 0 & 0 & 2 & 0 & 0 & 24 \\
\hline Total & 25 & 17 & 5 & 42 & 29 & 4 & 44 & 29 & 5 & 78 & 35 & 16 & 29 & 2 & 1 & 13 & 5 & 5 & 384 \\
\hline
\end{tabular}

Salmonella typhi continues to be a burden in most developing countries. Poor diagnosis has contributed to the deteriorating conditions as typhoid fever have common signs and symptoms similar to those of other common febrile illnesses. The blood culture and stool culture which are methods commonly used for the diagnosis of typhoid fever were done simultaneously to increase the probability and accuracy of detecting typhoid fever cases (Table 1). It is necessary to note that the use of the Widal test has been banned in many countries but it is still widely used in most health centers [16], [17] due to it unreliability [18]. 


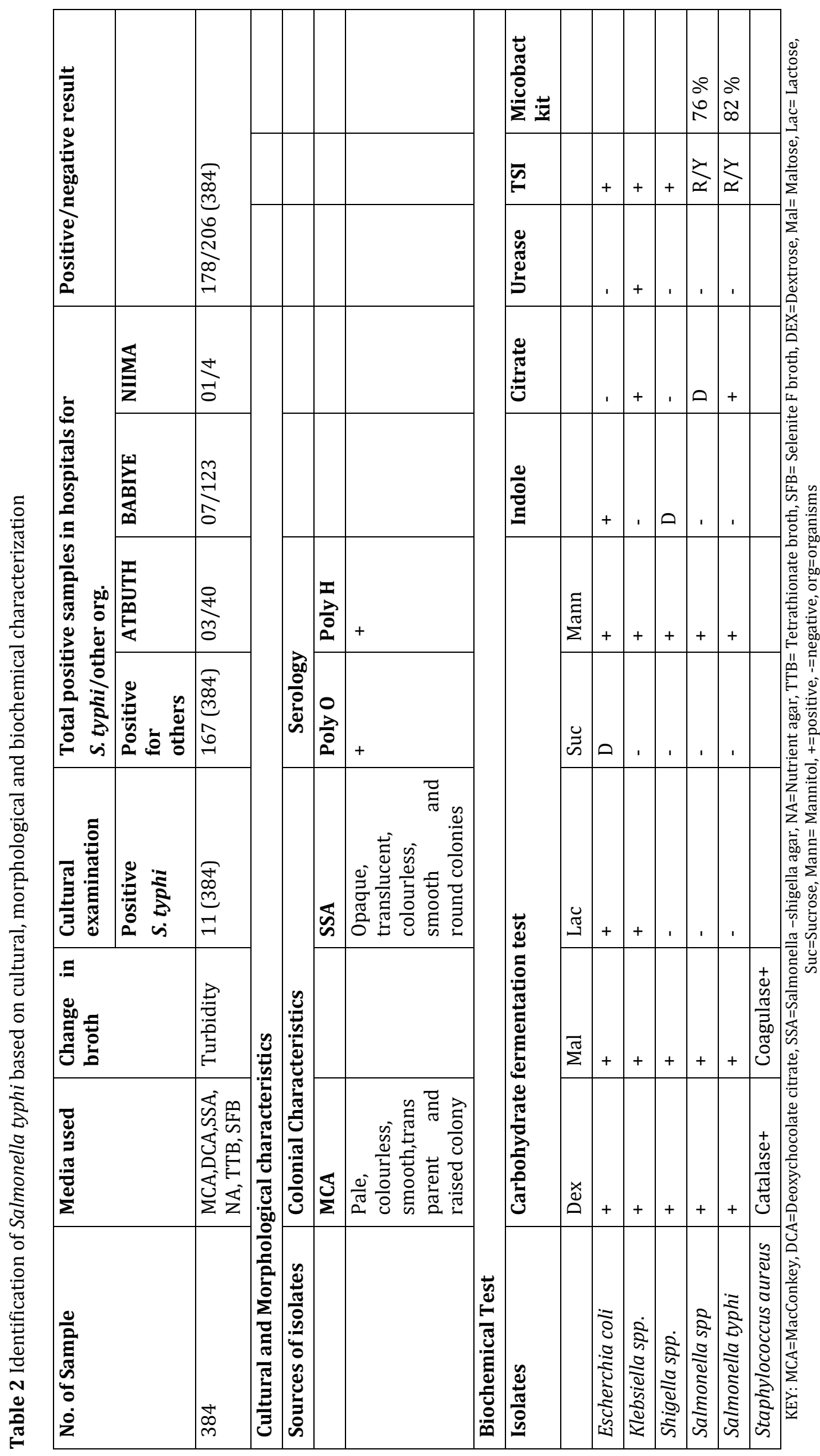


The findings indicate that febrile, diarrheic and febrile/diarrheic patients suspected of typhoid fever cases reported were diagnosed using the Widal test. However, the same patient's blood or stool culture did not confirm $S$. typhi isolate. In these particular patients, whose widal test was reactive, other bacterial organisms were isolated thus emphasizing the unspecific nature of the Widal test. A single widal test, using the slide test technique, is commonly used in the three health facilities where the study was carried out, for the diagnosis of typhoid bacteria (Table 2). Though widely used in such resource limited settings, it is not reliable and may produce false-positive results thus leading to over-diagnosis of typhoid fever. Its performance is affected by cross-reactions with other bacterial pathogens, previous immunization with Salmonella antigen, non-Salmonella infections such as malaria, Shigellosis, entero-toxigenic E. coli and other infectious organism that lead to an increase in the 0 antibodies [19]. Both gram negative and gram-positive bacteria were obtained from the clinical samples. All the isolates obtained from stool samples were all gram-negative bacteria while those from blood samples were a mixture of both gram positive and negative bacteria. Some blood cultures and stool cultures confirmed positive results for $S$. typhi from the study participants who showed signs and symptoms of typhoid fever infection. The specific bacterial pathogens isolated from the blood cultures include $S$. aureus, which correspond to the research of [20] among different sample group (Table 2).

Table 3 Distribution of Salmonella typhi and other Bacterial organism in stool and blood specimen of subject based on gender

\begin{tabular}{|c|c|c|c|c|c|c|}
\hline \multirow[t]{2}{*}{ Gender } & \multirow[t]{2}{*}{ Patient } & \multicolumn{2}{|c|}{ Stool $(n=135)$} & \multicolumn{2}{|c|}{ Blood $(n=249)$} & \multirow{2}{*}{$\begin{array}{l}\text { Positive/ } \\
\text { Negative }\end{array}$} \\
\hline & & S. typhi & Other Bacteria & S. typhi & Others Bacteria & \\
\hline \multirow[t]{3}{*}{ Male } & Febrile (98) & - & 30 & 1 & 13 & \\
\hline & Diarrhoeic (48) & 2 & 23 & - & 5 & \\
\hline & Febrile/diarrhoeic (11) & 1 & 4 & - & - & \\
\hline Total & 157 & 3 & 57 & 1 & 18 & $79 / 78$ \\
\hline \multicolumn{7}{|c|}{$P(0.827)^{a}$} \\
\hline \multirow[t]{3}{*}{ Female } & Febrile(133) & 1 & 43 & 2 & 14 & \\
\hline & Diarrhoeic (69) & 2 & 27 & - & 6 & \\
\hline & Febrile/diarrhoeic(25) & 1 & 1 & 1 & 1 & \\
\hline Total & 227 & 4 & 71 & 3 & 21 & $99 / 128$ \\
\hline$P(0.866)$ & & & & & & \\
\hline
\end{tabular}

\section{Conclusion}

Age and sex variation among the patients attending the selected health facilities shows high level of fever and diarraoea among the females of paediatric ages and the lowest was observed among the productive age range of 41-50 respectively. Despite the aforementioned case, it poses no significance to Salmonella typhi infection among the subjects. Escherichia coli was found to be the highest isolated organism from the stool specimen as it constitutes the zone of adaptation of many enteric organisms. The blood specimen continues to maintain a sterility status with mostly $S$. aureus as a predominant organism isolated from the suspected blood specimen respectively. The study had shown not all febrile case is related to typhoid inclusions in medical prognosis.

\section{Compliance with ethical standards}

\section{Acknowledgments}

The authors thank the University and the Teaching Hospital of the Abubakar Tafawa Balewa University, Bauchi for ethical clearance and approval.

\section{Disclosure of conflict of interest}

There's no what so ever any conflict of interest we are giving the outfit full right to publication of this work. 


\section{References}

[1] Selvaraj R, Das R, Ganguly S, Ganguli M, Dhanalakshmi S and Mukhopadhayay SK. (2010). Characterization and antibiogram of Salmonella spp. from poultry specimens. Journal of Microbiology and Antimicrobials, 2(9), 123126

[2] Buckle GC, Walker CL and Black RE. (2012). Typhoid fever and paratyphoid fever: Systematic review to estimate global morbidity and mortality for 2010. Journal of global health, 2(1).

[3] Kothari A, Pruthi A and Chung TD. (2008). The burden of enteric fever. Journal of Infection in Developing Countries, 2(4), 253-9.

[4] Yang R, Li Y, Dai E, Cui Y, Li M, Zhang Y, Wu M, Zhou D, Guo Z, Dai X, Cui B, Qi Z, Wang Z, Wang H, Dong X, Song, Z, Zhai J and Song Y. (2008). Different region analysis for genotyping Yersinia pestis isolates from China. Plos One, 3, 2166.

[5] Crump JA, Luby SP and Mintz ED. (2004). The global burden of typhoid fever. Bull World Health Organ, 82, 346353.

[6] Ibekwe AC, Okonko IO, Onunkwo AU, Donbraye E, Babalola ET and Onoja BA. (2008). Baseline Salmonella agglutinin titres in apparently healthy freshmen in Awka, South Eastern, Nigeria. Scientific Research and Essays, $3(9), 425-430$.

[7] Cabral JPS. (2010). Water Microbiology. Bacterial Pathogens and Water. International Journal of Environmental Research and Public Health, 201(7), 3657-3703.

[8] Walia M, Gaind R, Paul P, Mehta R, Aggarwal P and Kalaivani M. (2006). Age-related clinical and microbiological characteristics of enteric fever in India. Transactions of the Royal Society of Tropical Medicine and Hygiene, $100(10), 942-948$.

[9] Sur D, Ali M, von Seidlein L, Manna B, Deen JL, Acosta CJ, Clemens JD and Bhattacharya SK. (2007). Comparisons of predictors for typhoid and paratyphoid fever in Kolkata, India. BMC public health, 7(1), 289.

[10] Buxton A and Fraser G. (1977). Animal Microbiology. Blackwell Scientific Publications, Oxford. 1, 85-110.

[11] Hossain KM. (2002). Characterization of bacteria isolated from diarrhoeic calves. MS Thesis, Department of Microbiology and Hygiene, Bangladesh Agricultural University, Mymensingh.

[12] Han J, David DE, Deck J, Lynne AM, Kaldhone P, Nayak R, Stefanova R and Foley SL. (2011). Comparison of Salmonella enterica serovar Heidelberg isolates from human patients with those from animal and food sources. Journal of clinical microbiology, 49(3), 1130-1133.

[13] Adesiyun AA, Dasuki MO and Ibrahim GA. (1988). Occurrence and antibiograms of salmonellae isolated from slaughter sheep and goats in Zaria, Nigeria. Israel Journal of Veterinary Medicine, 44(4), 248-255.

[14] Zhang YX, Li JQ and Wang TG. (1998). Isolation and identification of Salmonella typhimurium and composition of its pathogenisity with Salmonella enteritidis. Chainese Journal of Veterinary Science and Technology, 28(9), 2627.

[15] FDA (2010). National Antimicrobial Resistance Monitoring System (NARMS) Enteric Bacteria Executive Report. U.S. Department of Health and Human Services, Food and Drug Administration (FDA), Rockville, MD.

[16] Kenyan Medical Laboratory Technicians and Technologies Board (KMLTTB), (2012). Setting the pace for quality laboratory standards in Kenya. Nairobi: KMLTTB.

[17] Smith SI, Fowora MA, Atiba A, Anejo-Okopi J, Fingesi T, Adamu ME, Omonigbehin EA, Ugo-Ijeh MI, Bamidele M and Odeigah P. (2015). Molecular detection of some virulence genes in Salmonella spp isolated from food samples in Lagos, Nigeria Animal and Veterinary Sciences, 3(1), 22-27.

[18] Egah DZ and Sule AZ. (2001). Bacterial isolates from blood culture and their antimicrobial susceptibility pattern. Afr J Clin Exp Microbiol, 1, 39-45.

[19] Ley B, Thriemer K, Ame SM, Mtove GM, von Seidlein L, Amos B, Hendriksen IC, Mwambuli A, Shoo A, Kim DR and Ochiai LR. (2011). Assessment and comparative analysis of a rapid diagnostic test (Tubex®) for the diagnosis of typhoid fever among hospitalized children in rural Tanzania. BMC infectious diseases, 11(1), 147. 
[20] Mureithi MW. (2010). Isolation and characterization of bacteria pathogens in blood and stool samples among patients presenting with typhoid fever symptoms in Alupe, Busia county. Centre for Infectious and Parasitic Diseases Control Research (CIPDCR) P.O.BOX 3, BUSIA-KENYA.

\section{How to cite this article}

Rabiu SM, Inusa T, Farouk AU and Ediga AB. (2018). Phenotypic characterization of Salmonella typhi isolated from febrile and diarrhea patients in Bauchi, Nigeria. GSC Biological and Pharmaceutical Sciences, 4(3), 61-67. 